\title{
New heart failure therapy: The shape of things to come?
}

Daniel Burkhoff, MD, PhD

From the Department of Medicine, Divisions of Circulatory Physiology and Cardiology, Columbia University, New York, NY.

Received for publication March 20, 2001; accepted for publication March 27, 2001.

Address for reprints: Daniel Burkhoff, MD, $\mathrm{PhD}$, Department of Medicine, Divisions of Circulatory Physiology and Cardiology, Columbia University, 812 Black Building, $650 \mathrm{~W}$ 168th St, New York, NY 10032.

J Thorac Cardiovasc Surg 2003;125:S50-2

Originally published in $\mathrm{J}$ Thorac Cardiovasc Surg 2001;122:421-3.

Copyright $\odot 2003$ by The American Association for Thoracic Surgery

$0022-5223 / 2003 \$ 30.00+0$

doi:10.1067/mtc.2003.222

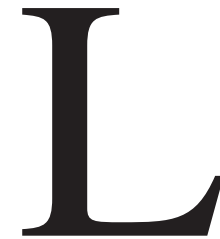

aplace's law, which can be used to estimate myocardial wall stress $(\sigma)$ from intraventricular pressure (LVP), radius of curvature $(\mathrm{R})$, and wall thickness (h), has long been recognized as a fundamental physical principle in understanding cardiac function in health and disease: $\sigma=\mathrm{LVP} \times \mathrm{R} / \mathrm{h}$. On the basis of this law, the enlarged chamber radius of the chronically failing heart exposes myocytes to increased systolic wall stress. This leads to cellular and chamber hypertrophy, which, in an adaptive process, acts to renormalize wall stress. ${ }^{1}$ As the chamber continues to dilate over time, the limits of hypertrophy appear to be reached so that wall stress ultimately increases. This increased afterload further impairs the ability of the already weakened myocytes to shorten, and cardiac performance deteriorates. Globally referred to as ventricular remodeling, this process is partially preventable and reversible as demonstrated in studies of angiotensin-converting enzyme inhibitors, ${ }^{2} \beta$-blockers, ${ }^{3}$ and during hemodynamic unloading by prolonged support with a left ventricular assist device. ${ }^{4}$

Several surgical therapies, such as the Myocor ventricular shape change device (Myocor, Inc, Plymouth, Minn), described in this issue by McCarthy and colleagues, ${ }^{5}$ are being developed for treating heart failure by physically remodeling the dilated heart. Stress reduction via Laplace's law is usually sited as the rationale for these therapies. The Batista procedure ${ }^{6}$ (partial left ventriculectomy for patients with idiopathic cardiomyopathy) is an important predicate example. Despite initial enthusiasm, clinical studies showed that although estimated wall stress was reduced, a majority of patients did not experience improved hemodynamics or clinical status in the long term. ${ }^{7}$ In my opinion, one limitation in thinking about this procedure was the focus on its potentially beneficial effects on wall stress to the exclusion of considering its effects on overall pump function. Specifically, the effects of myocardial resection on diastolic ventricular properties were under-appreciated. When expressed in terms of end-systolic and end-diastolic pressure-volume relationships (ESPVR and EDPVR, respectively), theory predicted ${ }^{8,9}$ and clinical research later showed ${ }^{10}$ that despite the potentially beneficial effects on systolic properties of shifting the ESPVR leftward (increased chamber contractility), the Batista procedure was also associated with counteracting effects on diastole. These were manifest as similar, or even greater, leftward shifts of the EDPVR with a net result of little net benefit on overall left ventricular pumping capacity (Figure 1, A). Hypothetically, it would be more desirable for a therapy to cause a larger leftward shift in the ESPVR than in the EDPVR (Figure 1, B), which would result in a greater ventricular pumping capacity. Furthermore, we argued that changes in ejection fraction resulting from reductions in end-diastolic volume without changes in stroke volume are not indicative of improved systolic function as they are in the setting of standard inotropic therapy. ${ }^{8}$

McCarthy and colleagues, who played a pivotal role in the systematic clinical evaluation of the Batista operation, ${ }^{11}$ have not abandoned the concept that radius of curvature reduction can have a favorable impact on ventricular function. The investigators used struts (Myosplint; Myocor, Inc) placed across the ventricle to pull opposing sides of the chamber together to alter ventricular shape and functionally separate the chamber into two lobes, each with a smaller radius than the original heart. ${ }^{5}$ An easy to understand explanation of how Laplace's law predicts systolic wall stress reduction by this shape change therapy is provided by the authors. This 

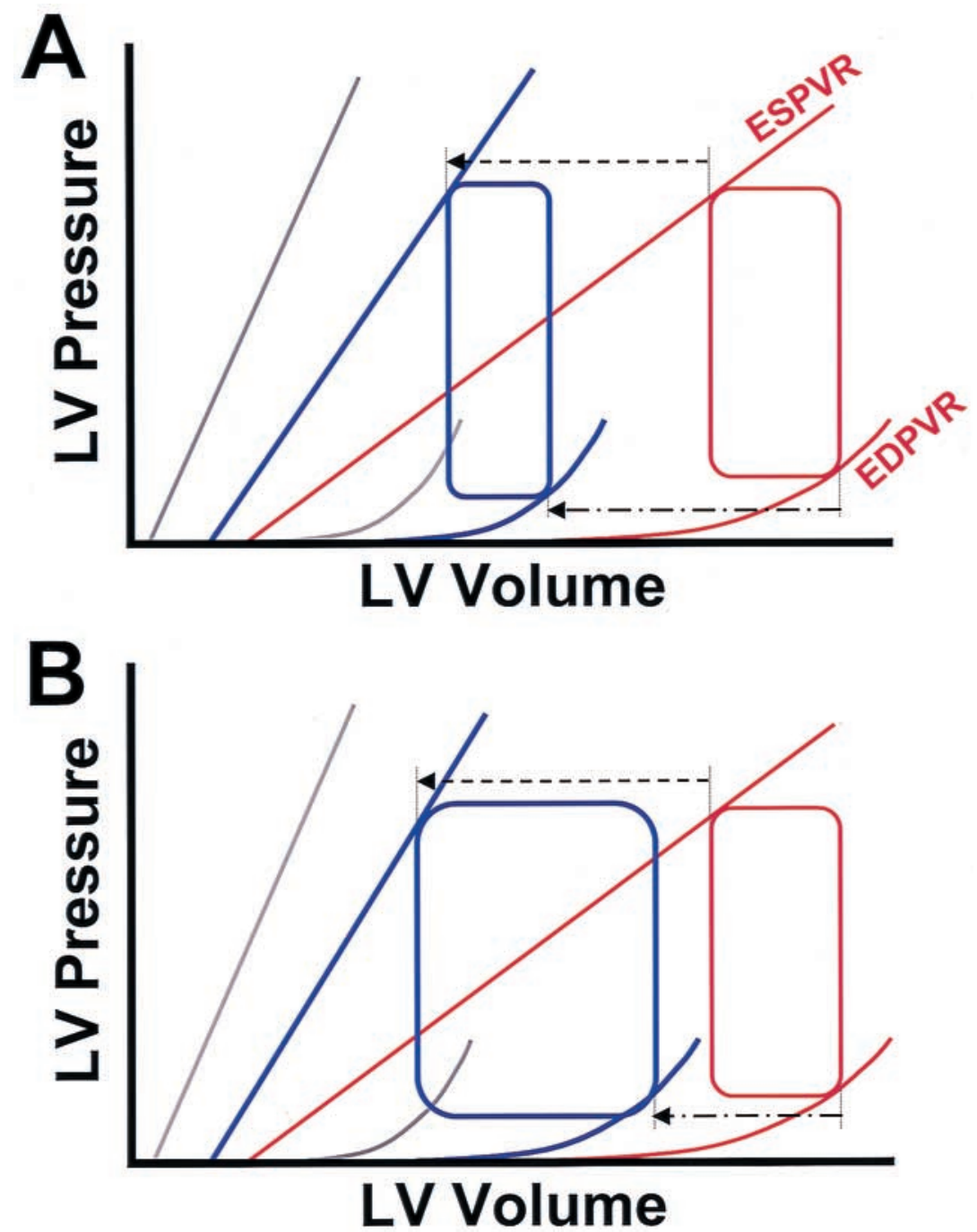

Figure 1. Ventricular pump properties are typically represented by ESPVR and EDPVR. In heart failure (red) both systolic and diastolic curves are shifted toward significantly larger volumes compared with normal (gray), a manifestation of ventricular remodeling. It was shown previously that with the Batista procedure (b/ue), and possibly for the Myosplint device, there is a rightward shift of the EDPVR that is slightly greater than the shift in the ESPVR (A), resulting in little change in net ventricular pump function as shown by the pressure-volume loops with similar stroke volumes at comparable end-diastolic and aortic pressures. This would contrast with a hypothetical therapy that would induce a greater leftward shift of the ESPVR than EDPVR and cause an increase in net pumping capacity (B), as shown by the pressure-volume loop (b/ue), with significantly increased stroke volume compared with the heart failure state (red) at comparable end-diastolic and aortic pressures.

concept is also supported by more sophisticated computational model analysis of the same concept performed by other investigators. ${ }^{12}$

Experimentally, McCarthy and associates show that, as intended, the Myosplint device reduces ventricular enddiastolic volume, end-systolic volume, and wall stress while increasing ejection fraction; these effects are sustained to the maximum time investigated, 1 month. However, there were no significant changes in cardiac output, end-diastolic pressure, or mean arterial pressure. These data indicate that there are leftward shifts (smaller volumes at similar pressures) in both ESPVR and EDPVR and furthermore suggest that the shifts of these relationships are likely to be relatively balanced so that there is little net effect on overall pump function (as in Figure 1, $A$ ). With no acute or possibly even chronic hemodynamic benefit, pivotal questions include whether the Myosplint device actually resulted in regression of hypertrophy (wall thickness and heart mass data would be of interest) and whether any such changes would translate into clinically meaningful effects on patient 
symptoms, disease progression, and/or mortality. The latter are difficult issues to address in preclinical studies.

As noted above, several forms of surgical therapies are being investigated to physically remodel the failing heart, including other passive devices ${ }^{13}$ and resection of akinetic scars. ${ }^{14}$ There is a need to better define the effects of such procedures on a broad range of mechanical and biochemical properties of the heart; consideration of effects on wall stress alone may not reveal the entire picture. The importance of improved understanding stems at least in part from the need for physicians considering referring their patients for clinical trials to be able to assess the potential that a surgical heart failure therapy with little (if any) acute hemodynamic benefits will ultimately translate into clinical benefits. Could this be the case for a therapy that changes the shape of the failing heart? If such benefits were confirmed by careful clinical investigation, surgeons could have a means of meaningfully affecting the heart failure epidemic and change the shape of heart failure treatment in the future.

\section{References}

1. Hunter JJ, Chein KR. Signaling pathways for cardiac hypertrophy and failure. N Engl J Med. 1999;341:1276-83.

2. Greenberg B, Quinones MA, Koilpillai C, Limacher M, Shindler D, Benedict $\mathrm{C}$, et al. Effects of long-term enalapril therapy on cardiac structure and function in patients with left ventricular dysfunction: results of the SOLVD echocardiography substudy. Circulation. 1995; 91:2573-81.

3. Lechat P, Packer M, Chalon S, Cucherat M, Arab T, Boissel JP. Clinical effects of beta-adrenergic blockade in chronic heart failure: a meta-analysis of double-blind, placebo-controlled, randomized trials. Circulation. 1998;98:1184-91.
4. Levin HR, Oz MC, Chen JM, Packer MP, Rose EA, Burkhoff D. Reversal of chronic ventricular dilation in patients with end-stage cardiomyopathy by prolonged mechanical unloading. Circulation. 1995;91:2717-20.

5. McCarthy PM, Fukamachi K, Takagaki M, Ochiai Y, Young JB, Tabata T, et al. Device-based change in left ventricular shape: a new concept for the treatment of dilated cardiomyopathy. J Thorac Cardiovasc Surg. 2001;122:482-90.

6. Batista RJ, Verde J, Nery P, Bocchino L, Takeshita N, Bhayana JN, et al. Partial left ventriculectomy to treat end-stage heart disease. Ann Thorac Surg. 1997;64:634-8.

7. Franco-Cereceda A, McCarthy PM, Blackstone EH, Hoercher KJ, White JA, Young JB, et al. Partial left ventriculectomy for dilated cardiomyopathy: Is this an alternative to transplantation? J Thorac Cardiovasc Surg. 2001;121:879-93.

8. Dickstein ML, Spotnitz HM, Rose EA, Burkhoff D. Heart reduction surgery: an analysis of the impact on cardiac function. $J$ Thorac Cardiovasc Surg. 1997;113:1032-40.

9. Ratcliffe MB, Hong J, Salahieh A, Ruch S, Wallace AW. The effect of ventricular volume reduction surgery in the dilated, poorly contractile left ventricle: a simple finite element analysis. $J$ Thorac Cardiovasc Surg. 1998;116:566-77.

10. Schreuder JJ, Steendijk P, van der Veen FH, Alfieri O, van der NT, Lorusso R, et al. Acute and short-term effects of partial left ventriculectomy in dilated cardiomyopathy: assessment by pressure-volume loops. J Am Coll Cardiol. 2000;36:2104-14.

11. McCarthy JF, McCarthy PM, Starling RC, Smedira NG, Scalia GM, Wong J, et al. Partial left ventriculectomy and mitral valve repair for end-stage congestive heart failure. Eur J Cardiothorac Surg. 1998;13: $337-43$.

12. Melvin DB. Ventricular radius reduction without resection: a computational analysis. ASAIO J. 1999;45:160-5.

13. Power JM, Raman J, Dornom A, Farish SJ, Burrell LM, Tonkin AM, et al. Passive ventricular constraint amends the course of heart failure: a study in an ovine model of dilated cardiomyopathy. Cardiovasc Res. 1999;44:549-55.

14. Dor V, Sabatier M, Di Donato M, Montiglio F, Toso A, Maioli M. Efficacy of endoventricular patch plasty in large postinfarction akinetic scar and severe left ventricular dysfunction: comparison with a series of large dyskinetic scars. J Thorac Cardiovasc Surg. 1998;116: $50-9$. 